\title{
BMJ Open Respiratory and circulatory insufficiency during emergent long-distance critical care interhospital transports to tertiary care in a sparsely populated region: a retrospective analysis of late mortality risk
}

Marcus Fredriksson Sundbom (D) , Amalia Sangfelt, Emma Lindgren, Helena Nyström, Göran Johansson, Helge Brändström, Michael Haney

To cite: Fredriksson Sundbom M, Sangfelt A, Lindgren $\mathrm{E}$, et al. Respiratory and circulatory insufficiency during emergent long-distance critical care interhospital transports to tertiary care in a sparsely populated region: a retrospective analysis of late mortality risk. BMJ Open 2022;12:e51217. doi:10.1136/ bmjopen-2021-051217

- Prepublication history and additional supplemental material for this paper are available online. To view these files, please visit the journal online (http://dx.doi.org/10.1136/ bmjopen-2021-051217).

Received 14 March 2021 Accepted 03 February 2022

Check for updates

(c) Author(s) (or their employer(s)) 2022. Re-use permitted under CC BY-NC. No commercial re-use. See rights and permissions. Published by BMJ.

Department of Surgical and Perioperative Sciences/ Anesthesiology and Intensive Care Medicine, Umeå University, Umeå, Sweden

Correspondence to

Dr Marcus Fredriksson

Sundbom;

marcus.fredriksson.sundbom@ umu.se

\section{ABSTRACT}

Objectives To test if impaired oxygenation or major haemodynamic instability at the time of emergency intensive care transport, from a smaller admitting hospital to a tertiary care centre, are predictors of long-term mortality.

Design Retrospective observational study. Impaired oxygenation was defined as oxyhaemoglobin \%inspired oxygen fraction ratio (S/F ratio) $<100$. Major haemodynamic instability was defined as a need for treatment with norepinephrine infusion to sustain mean arterial pressure (MAP) at or above $60 \mathrm{~mm} \mathrm{Hg}$ or having a mean MAP $<60$. Logistic regression was used to assess mortality risk with impaired oxygenation or major haemodynamic instability.

Setting Sparsely populated Northern Sweden. A fixedwing interhospital air ambulance system for critical care serving 900000 inhabitants.

Participants Intensive care cases transported in fixedwing air ambulance from outlying hospitals to a regional tertiary care centre during 2000-2016 for adults (16 years old or older). 2142 cases were included.

Primary and secondary outcome measures All-cause mortality at 3 months after transport was the primary outcome, and secondary outcomes were all-cause mortality at 1 and 7 days, 1, 6 and 12 months.

Results S/F ratio $<100$ was associated with increased mortality risk compared with $S / F>300$ at all time-points, with adjusted OR 6.3 (2.5 to $15.5, p<0.001)$ at 3 months. Major haemodynamic instability during intensive care unit (ICU) transport was associated with increased adjusted OR of all-cause mortality at 3 months with OR 2.5 (1.8 to 3.5, $\mathrm{p}<0.001$ ).

Conclusion Major impairment of oxygenation and/ or major haemodynamic instability at the time of ICU transport to get to urgent tertiary intervention is strongly associated with increased mortality risk at 3 months in this cohort. These findings support the conclusion that these conditions are markers for many fold increase in risk for death notable already at 3 months after transport for patients with these conditions.

\section{Strengths and limitations of this study}

- Complete case analysis and no loss to follow-up.

- Data collected over 16 years which enables a large number of cases to be studied.

- No comorbidity or disease severity data which inhibits adjustment for these confounders.

- A single transport system which limits generalisability.

- All-cause mortality which prevents any conclusion as to the actual cause of death.

\section{BACKGROUND AND AIMS}

For sparsely populated regions in highincome countries, advanced specialty and subspecialty care are often centralised to larger hospitals. This means that when patients become critically ill, and then need highly specialised care which is only available in regional tertiary and quaternary hospitals, they need to be transferred urgently to these regional centres. When distances are great between hospitals, this transport is most efficiently managed by an air ambulance system adapted for providing critical care during transport. For longer distance transports, fixed-wing ambulance systems are more costeffective than helicopter emergency medical systems. ${ }^{1}$ Inter-hospital critical care transports in northern Sweden are carried out by specialised teams of anaesthesiology/intensive care physicians and nurses, and the fixedwing air ambulance critical care transport system is based at the University Hospital of Umeå.

Critically ill patients often suffer from a range of physiological derangements, which require advanced medical management 


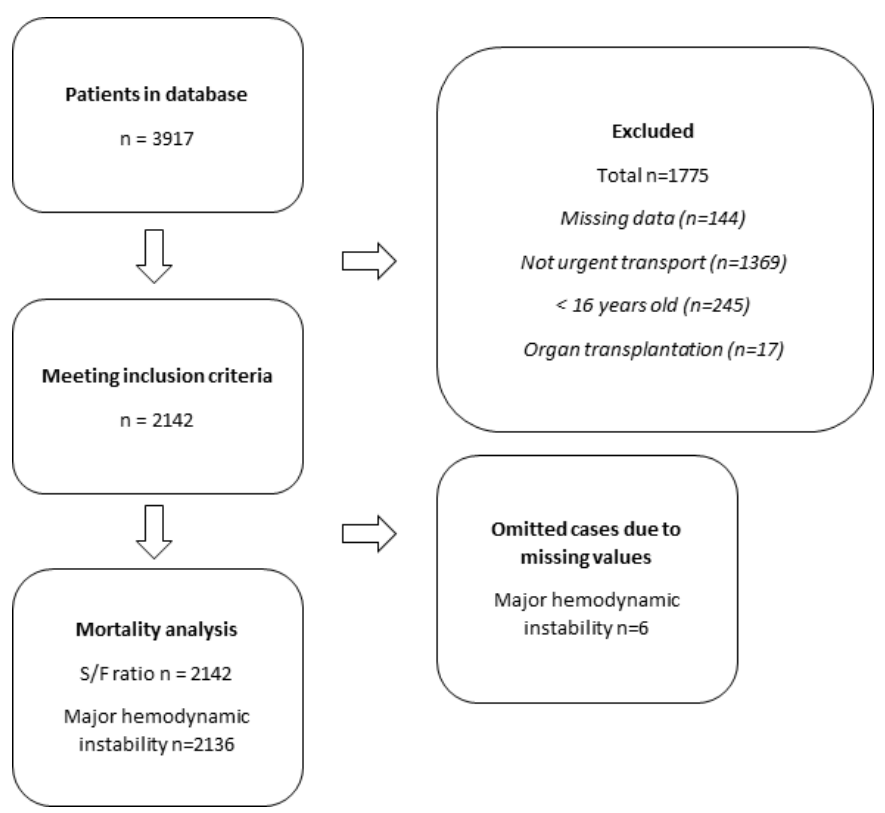

Figure 1 Flowchart of patient selection for this study. S/F, oxyhaemoglobin \% and inspired oxygen fraction ratio.

during the transport, but also might contribute to risk for reduced later survival. Impaired gas exchange in the lungs leading to end-organ stress or injury is common among critically ill patients. A hypoxaemic tendency can be seen in up to $15 \%$ of those who arrive to the hospital after air ambulance transport. ${ }^{2}$ Endotracheal intubation and mechanical ventilation may improve oxygenation at the time of transport, but hypoxaemia is still seen in up to $3 \%$ at arrival to hospital. ${ }^{34}$ Circulatory disturbances are also common, and are often present at the same time as hypoxaemia, which is associated with higher mortality. ${ }^{5}$ Up to $10 \%$ of patients may be hypotensive when arriving to hospital with air ambulance. ${ }^{4}$

The clinical question in this study involves mortality risks for this specific mixed cohort from a very large geographic region which requires an advanced transport system to allow access to definitive tertiary care when severe injury or severe acute illness occurs. This can be a form of benchmarking and assessment of regional cooperative performance to allow survival for acutely critically ill patients. There may be characteristics about the region studied here, the case-cohort, or the hospital services which influence patient survival, yet be difficult to measure. The assessment here is on an empirical basis using case characteristics available only during the emergency intensive care unit (ICU) transport, which might allow generalisation of possible findings to healthcare systems.

We hypothesised that impaired oxygenation and major haemodynamic instability both independently are associated with increased risk for all-cause mortality at 3 months. A secondary hypothesis is that the same would be associated with increased risk all-cause mortality up to 12 months after transport.

\section{METHODS}

\section{Study population}

The anonymised study cohort database was generated from the Departmental (air ambulance) patient registry for critically ill patients undergoing fixed-wing air ambulance transportation to the University Hospital of Umeå, and linkage to date of death data from the Swedish National Board of Health and Welfare. Inclusion was for all cases during 2000-2016 for ages 16 years or older from missions originating from local hospitals in the northern healthcare region of Sweden to take patients emergently for more definitive care at the regional tertiary care centre. Exclusion criteria included the following: cases with transport solely for organ transplantation purposes, missing data, non-urgent transports, patients without a Swedish personal identity number (not in the national citizen registry).

\section{Patient and public involvement}

No patient involved.

\section{Setting}

The Swedish northern healthcare region consists of the four northern-most counties of Sweden; Norrbotten, Västerbotten, Västernorrland and Jämtland, which make up a total of approximately 900000 inhabitants over 210 $000 \mathrm{~km}^{2}$, where each county has smaller hospitals. The fixed-wing ICU transport system at the regional tertiary facility, the University Hospital of Umeå have teams that are active around the clock, every day, to provide rapid response times for emergency ICU patient transports. The flights are staffed by a physician and a nurse specialised in anaesthesiology and intensive care. Transport logistics are coordinated centrally, including road ambulance between hospitals and airports.

\section{Data}

Case factors included in the analysis are age, sex, diagnostic group, total transport time, mode of breathing (eg, endotracheal intubation) and physiological data such as blood pressure, heart rate and oxygen saturation measured by pulse oximetry ( $\mathrm{SpO} 2)$. To assess oxygenation status among the patients where there were simplified ventilator FiO2 (fraction of inspired oxygen) settings during transport as well as limited blood gas data during transport, the ratio of pulse oximetry oxyhaemoglobin per cent and inspired oxygen fraction $(\mathrm{SpO} 2 / \mathrm{FiO} 2, \mathrm{~S} / \mathrm{F})$ was used. The threshold for defining the impaired oxygenation category $(\mathrm{S} / \mathrm{F}<100)$ degree of oxygenation impairment was chosen with support from the Berlin criteria for acute respiratory distress syndrome (ARDS). ${ }^{6}$ The definition of major haemodynamic instability as a binary outcome was where norepinephrine infusion was implemented to achieve a mean arterial pressure (MAP) $>60$ $\mathrm{mm} \mathrm{Hg}$ or a mean MAP $<60 \mathrm{~mm} \mathrm{Hg}$.

\section{Outcomes}

The primary outcome was all-cause mortality at 3 months after their emergency interhospital ICU transport. 
Table 1 Characteristics of the cohort

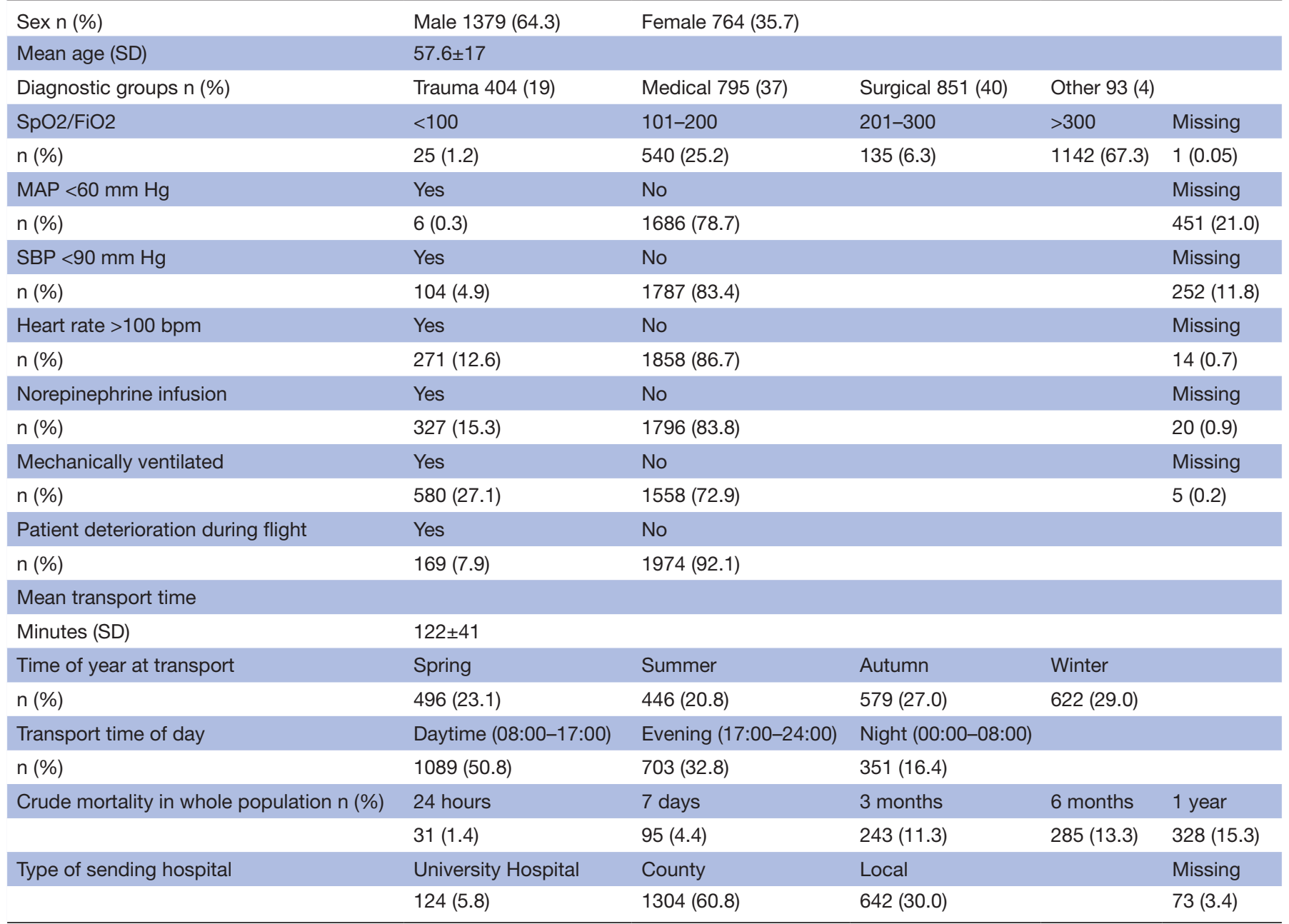

MAP, mean arterial pressure; SBP, systolic blood pressure.

Secondary outcomes were all-cause mortality at 6 and 12 months.

\section{Statistical analysis}

Statistical analysis was carried out using SPSS (IBM Corp. Released 2017. IBM SPSS Statistics for Windows, V.25.0: IBM Corp). Power analysis was carried out on the expected sample size of 2000 patients (PASS 15 Power Analysis and Sample Size Software 2017. NCSS, LLC, Kaysville, Utah, USA). A power of $93 \%$ with 0.05 significance was calculated based on 2000 cases total from exposed (cardiopulmonary insufficiency) and unexposed groups, with a presumed HR of 2 for mortality within 3 months. Shapiro-Wilks test was used to assess normal distribution, after which for non-normally distributed data, the nonparametrical Mann-Whitney $\mathrm{U}$ test was used to test the null hypothesis with ordinal/continuous data. $\chi^{2}$ and Fisher's exact test were used for nominal data. Logistic regression was used to estimate mortality risk (OR) for different levels of oxygenation and circulatory disturbances. Adjustments for sex, age, diagnostic groups and transport time were included in the regression model, and relative risks are presented with $95 \%$ CIs. Complete case analysis was used.

\section{RESULTS}

There were 3917 unique cases identified in the database, of which 1775 did not meet inclusion criteria (figure 1), providing 2142 cases for further analysis. In the analysis for major haemodynamic instability, six cases were excluded for incomplete data, leaving 2136 cases for that analysis.

\section{Characteristics of the cohort}

Patient characteristics show a higher proportion of males $(64.3 \%)$ (table 1$)$. The most common diagnostic groups were surgical $(40 \%)$, medical $(37 \%)$ while trauma accounted for $19 \%$ of the cohort. The mean age was 57.6 years. Most patients spontaneously maintained a mean MAP $>60(78.6 \%)$, and did not require norepinephrine infusion (83.8\%). Almost 13\% had tachycardia (heart rate $>100$ beats $/ \mathrm{min}$ ) and $4.9 \%$ a systolic blood pressure $<90 \mathrm{~mm} \mathrm{Hg}$. The most commonly observed $\mathrm{S} / \mathrm{F}$ ratio was 
Table 2 Logistical regression results, degrees of oxygenation impairment and mortality risk

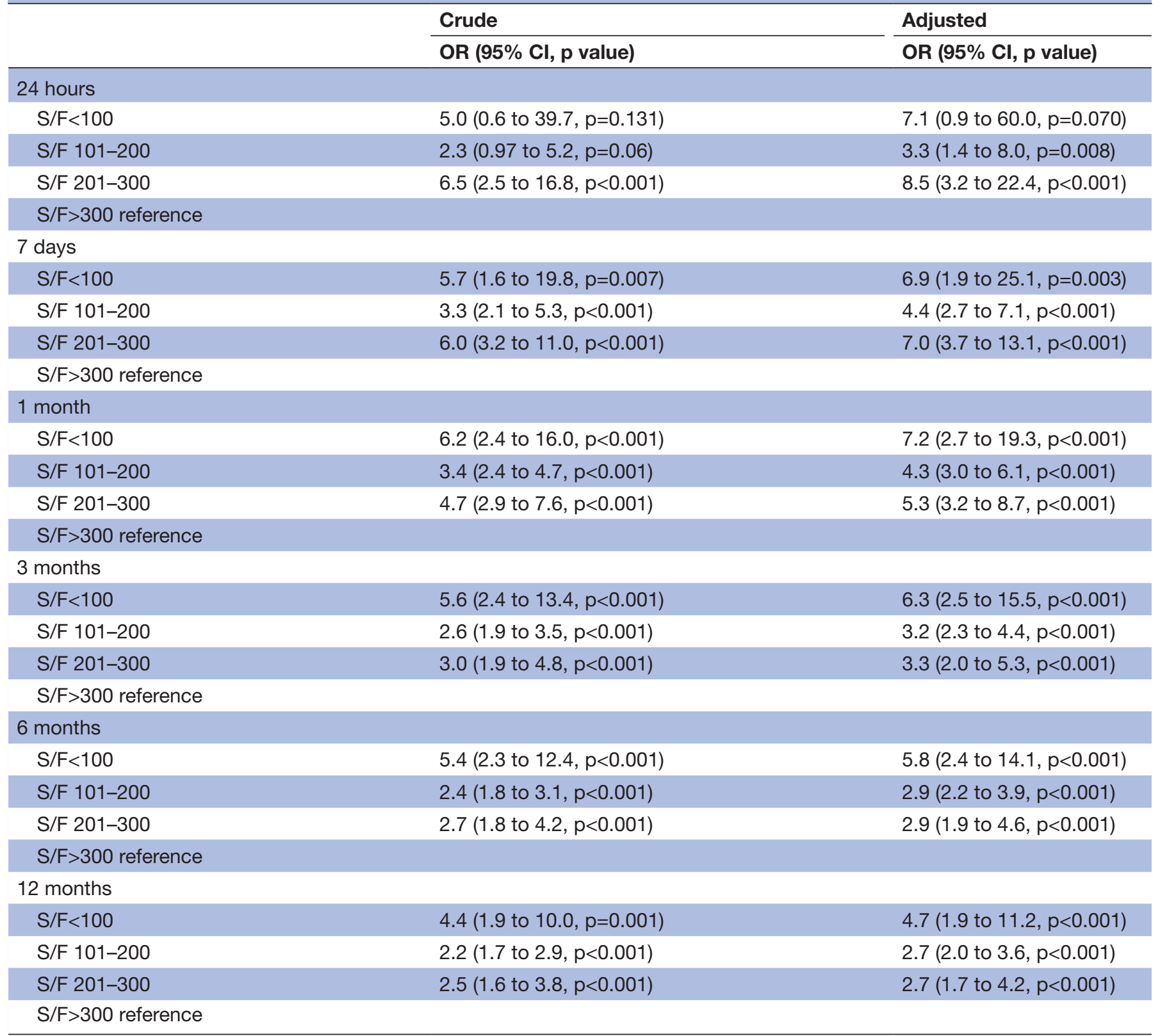

Adjusted models at all intervals included sex, age, diagnostic group and transport time.

$\mathrm{S} / \mathrm{F}$, oxyhaemoglobin \% and inspired oxygen fraction ratio.

$>300(\mathrm{n}=67.3 \%)$. Approximately one-third of the cases had severely disturbed gas exchange for oxygen. Mean transport times were more than 120 min.

Impaired oxygenation and major haemodynamic instability

The main findings for the lowest oxygenation group $(\mathrm{S} / \mathrm{F}<100)$ was that there was an increased adjusted OR $(6.3,95 \%$ CI 2.5 to $15.5, \mathrm{p}<0.001)$ for mortality over the first 3 months after the ICU transport compared with the normal oxygenation group $(\mathrm{S} / \mathrm{F}>300)$ (table 2$)$. Secondary findings for mortality within 24 hours did not show increased mortality risk for cases with worst oxygenation, but an indication possible increased risk for cases needing norepinephrine infusions during transport (table 3). At 7 days and 1 month posttransport, the secondary analysis shows increased mortality risk for both most impaired oxygenation and norepinephrine need during transport. Crude (online supplemental figure S1) as well as sex-adjusted and ageadjusted Kaplan-Meier plots (figure 2) demonstrate cumulative survival over time for both the oxygenation and the norepinephrine treatment groupings. Cumulative survival for the $\mathrm{S} / \mathrm{F}>300$ group at 12 months was $89 \%$ whereas it was $64 \%$ in the $\mathrm{S} / \mathrm{F}<100$ group, while being $78 \%$ and $76 \%$ in the S/F 101-200 and 201-301 groups. Notably, there is a clear separation between the best and worst oxygenation groups, but not in the 
Table 3 Logistical regression results, major haemodynamic instability present and mortality

\begin{tabular}{|c|c|c|}
\hline & Crude & Adjusted \\
\hline & OR (95\% Cl, p value) & OR (95 \% Cl, p value) \\
\hline 24 hours & 2.4 (1.1 to $5.3, p=0.032)$ & $3.2(1.4$ to $7.2, p=0.006)$ \\
\hline 7 days & $2.9(1.8$ to $4.5, p<0.001)$ & $3.3(2.1$ to $5.3, p<0.001)$ \\
\hline 1 month & $2.9(2.1$ to $4.1, p<0.001)$ & $3.2(2.2$ to $4.5, p<0.001)$ \\
\hline 3 months & $2.4(1.8$ to $3.3, p<0.001)$ & 2.5 (1.8 to $3.5, p<0.001)$ \\
\hline 6 months & $2.3(1.7$ to $3.0, p<0.001)$ & 2.3 (1.7 to $3.2, p<0.001)$ \\
\hline 12 months & 2.0 (1.5 to $2.7, p<0.001)$ & 2.1 (1.5 to $2.8, p<0.001)$ \\
\hline
\end{tabular}

Adjusted models at all intervals included sex, age, diagnostic group and transport time.

intermediate groups. There was early in clear separation in cumulative survival in the haemodynamic instability groups.

Absolute numbers of mortality events at different intervals are presented in table 4 , showing there were differences in mortality incidence between diagnostic groups.
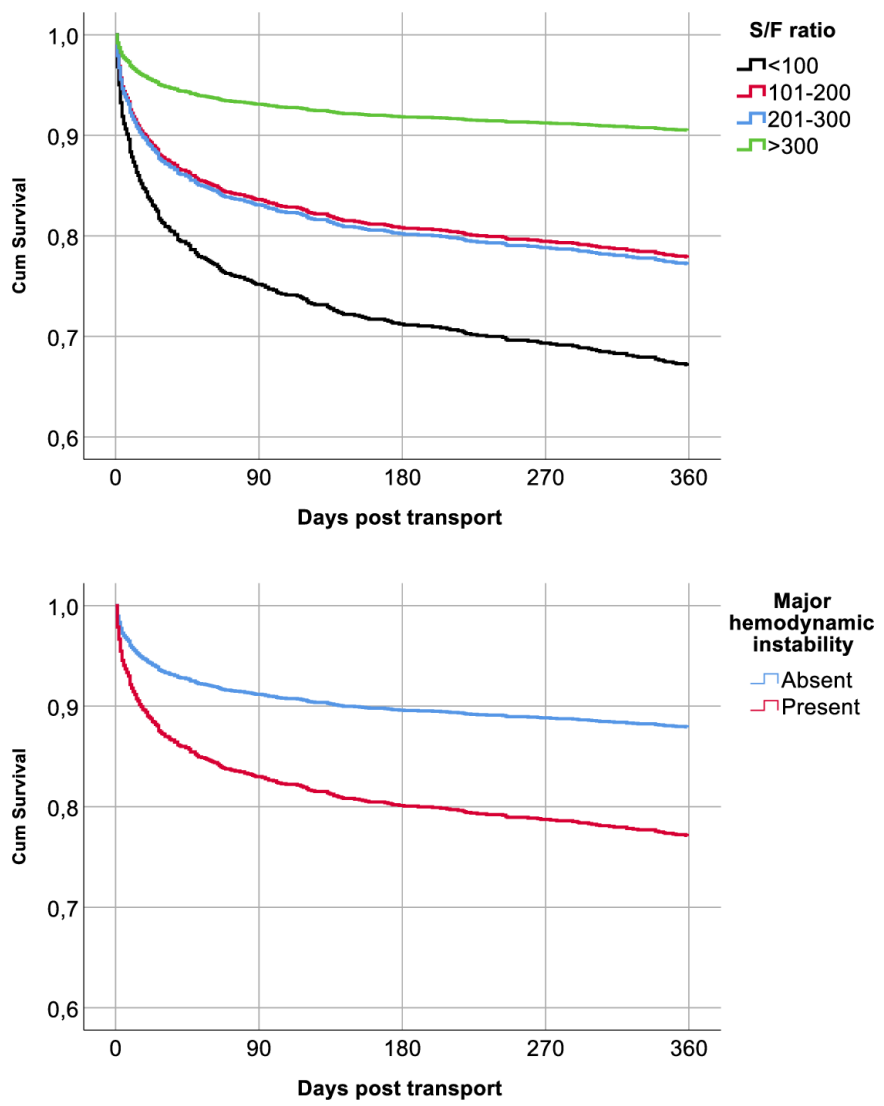

Figure 2 Cumulative survival in impaired oxygenation and major haemodynamic instability. Sex and age adjusted. Upper panel: different SpO2/FiO2 ratios and cumulative survival up to 12 months, $n=2142$. Lower panel: presence or absence of major haemodynamic and cumulative survival up to 12 months, $n=2136$. S/F, oxyhaemoglobin \% and inspired oxygen fraction ratio.
Simultaneous impaired oxygenation and major hemodynamic instability

There were only 13 cases where both of these exposures were present in the same case, and these demonstrated an OR for mortality risk which was in between the factor subgroups (online supplemental table $\mathrm{S} 1$ ). The increased adjusted risk, was OR 3.2 (0.9 to $11.1, \mathrm{p}=0.07)$ at the primary assessment interval (3 months).

A secondary analysis is presented for whole cohort mortality, including adjustments for age, sex, transport time, diagnostic group, season, time of day and sending hospital type (online supplemental table S2), where time of day was associated with increased early mortality. An additional secondary analysis including time of transport initiation (daytime, evening or night) is shown in table 5 , where transports initiated outside of regular work hours were associated with a much higher mortality risk.

\section{DISCUSSION}

In this retrospective cohort analysis, long-term mortality risk is quantified for both impaired oxygenation and major haemodynamic instability at the time of fixed-wing emergency air ambulance ICU transport. This cohort is clinically relevant concerning possible long-term effects of care and conditions in the early phase because it is the primary transport to tertiary care, rather than simply long distance transport of intensive care patients who may have already been definitively treated. The main finding is that the mortality risk within 90 days is particularly high for major oxygenation impairment, approximately six times, that of those who had no oxygenation impairment. The mortality risk for circulatory instability for the same time period is also approximately doubled compared with those not demonstrating circulatory instability. This impact on survival is despite early and aggressive intensive care. The relative mortality risks for cases with these conditions is in general agreement with those presented in some recent reports for shorter distance, rotary-wing ambulance, primary transports with ICU character. ${ }^{378}$

The cases in this cohort were transports initiated based on acute illness or injuries which occurred to get from initial resuscitation at a local hospital in a sparsely populated region, to tertiary or quaternary care at the regional university hospital. In this, there was an inevitable time interval between critical illness debut and implementation of some forms of specialty care, including specialty interventions in the university hospital. Still, there was always advanced general intensive care provided at the local hospital. The transport step also involved best possible provision of the same level of intensive care during the transfer from local to university hospital, although with crude ventilator settings ( $\mathrm{FiO} 21.0$ or 0.6$)$ and no possibility to assess arterial blood gas. Significant mortality risk is associated with different conditions at the start of need for critical care, including for example different forms of shock. ${ }^{9-12}$ 
Table 4 Number of mortality events per diagnostic group at different timepoints post-transport

\begin{tabular}{|c|c|c|c|c|c|c|}
\hline \multirow[b]{2}{*}{ Timepoint } & \multicolumn{5}{|c|}{ Diagnostic group } & \multirow[b]{2}{*}{$P$ value } \\
\hline & Surgical & Medical & Trauma & Other & Total & \\
\hline 24 hours & $20 / 874(2 \%)$ & $5 / 714(0.7 \%)$ & $4 / 404(1 \%)$ & 2/151 (1\%) & $31 / 2143(1 \%)$ & 0.052 \\
\hline 1 month & $106 / 874(12 \%)$ & $28 / 714(4 \%)$ & $29 / 404(7 \%)$ & $19 / 151(13 \%)$ & $182 / 2143(8 \%)$ & $<0.001$ \\
\hline 3 months & 137/874 (16\%) & $41 / 714(6 \%)$ & $39 / 404$ (10\%) & 26/151 (17\%) & $242 / 2143(11 \%)$ & $<0.001$ \\
\hline 12 months & 182/692 (21\%) & 62/714 (9\%) & $52 / 404(13 \%)$ & $32 / 151(21 \%)$ & $328 / 2143$ (15\%) & $<0.001$ \\
\hline
\end{tabular}

Pearson $\chi^{2}, \mathrm{df}=3$, used to compare proportions between diagnostic groups.

The quantification of the exposures here, respiratory and circulatory impairment, were chosen based on the available physiological data recorded in the patient records. It would have been optimal to have serial blood gases and close adjustments in ventilatory parameters to be very precise about alveolar-arterial oxygen gradients, but these were not generally available for this cohort. The $\mathrm{S} / \mathrm{F}$ index ${ }^{1314}$ was available for all the cases, and provided for reliable separation of these cases with highly impaired lung gas exchange for oxygen, as well as for those with no oxygenation impairment. The $\mathrm{S} / \mathrm{F}$ groups in-between may be less precise or crude as far as for quantifying oxygenation, but still an apparent dose effect of oxygenation impairment was demonstrated in the mortality risk analysis for these middle ranges. Concerning impaired circulation, further corroborating measures of inadequate circulation would have helped to confirm precision in this grouping. Norepinephrine infusion treatment may have been present for some cases for different reasons: for inadequate fluid resuscitation, for counter-acting sedativerelated blood pressure effects, or for other reasons. It was chosen, along with observed low MAP, as a category with this understanding that there might be a number of cases included in the group which were not due to primary circulatory insufficiency, but still had a norepinephrine infusion, which would dilute the results related to those with true shock. The possible effect of this on the analysis would be to underestimate the effect of haemodynamic instability as observed here on mortality.

The absolute mortality rate within 90 days of transport in the most impaired oxygenation group $(\mathrm{S} / \mathrm{F}<100)$ was approximately $25 \%$. This can be appreciated together with what is widely recognised as the high mortality risk associated with ARDS. ${ }^{1516}$ These were not cases of ARDS, at least at the time of transport. Compared with other studies of tertiary interhospital transports of severely hypoxaemic patients, the mortality rate is lower in our cohort, ${ }^{17-19}$ while being higher than long-term mortality rates in secondary interhospital transferred trauma patients at 3,6 and 12 months. ${ }^{20-22}$ Of course, expected mortality will be based on a number of different patient factors, including age, comorbidity, extent of injury or illness and more. One of the goals of this study was to generate a benchmark for just this kind of centralisation for advanced acute care in a very large geographical region. The relative risk analysis in this study was based only on clinical conditions at the time of transport, which was at the beginning of the hospitalisation period.

Notable secondary results include findings that support an interpretation that time of day for initiation of an unplanned critical care transport may be a good marker for very high risk for early mortality or inability to derive benefit from either the tertiary care definitive treatment or even the transport itself. This finding is explorative and would need to be confirmed in a larger database where precritical illness comorbidity and more detailed acute critical illness physiological details were included in the analysis.

One limitation in the study design was that preemergency ICU transport comorbidity and severity of illness data was not available for this analysis, where these are well-recognised as risk factors for mortality. ${ }^{23-26}$ If these had been available, they could possibly improve the precision of the risk estimates.

Table 5 Transport initiation time of day and mortality risk

\section{Adjustment}

\begin{tabular}{llll} 
Timepoint & Degree of oxygenation & Major haemodynamic instability & \begin{tabular}{l} 
haemodynamic instability \\
\hline 24 hours
\end{tabular} \\
\hline days & $2.06(1.30$ to $3.27, p=0.002)$ & $2.1(1.32$ to $3.32, p=0.002)$ & $2.0(1.27$ to $3.26, p=0.003)$ \\
\hline 3 days & $1.27(0.97$ to $1.66, p=0.078)$ & $1.3(1.02$ to $1.73, p=0.037)$ & $1.3(0.96$ to $1.64, p=0.096)$ \\
\hline
\end{tabular}

Results presented as OR and $95 \% \mathrm{Cl}$. 


\section{CONCLUSION}

In summary, this first analysis of our fixed-wing cohort has quantified relative mortality risks related to these two conditions in cases at the point of emergent long-distance critical care transport in the start of an intensive care treatment period. From these findings, we conclude that major impairment of oxygenation and/or major haemodynamic instability at the time of ICU transport in this setting is strongly associated with increased mortality risk at 3 months after the transport. These conditions may be markers for this many-fold increase in risk for death notable already at 3 months after transport. How much this risk is modifiable is not assessable in this analysis.

Contributors MFS contributed to the planning, data collection and analysis, and the writing and approval of the final manuscript. AS contributed to the planning, data collection and analysis, and the writing and approval of the final manuscript. EL contributed to the planning, data collection and analysis, and the writing and approval of the final manuscript. HN contributed to the planning, and the writing and approval of the final manuscript. GJ contributed to the planning, data collection and analysis, and the writing and approval of the final manuscript. HB contributed to the planning, data collection and the writing and approval of the final manuscript. $\mathrm{MH}$ contributed to the planning, data collection and analysis, and the writing and approval of the final manuscript. All authors read and approved the final manuscript. MFS and MH are the guarantors of the manuscript.

Funding This study was funded by intramural funding for the study of Air ambulance Intensive care from the County Healthcare Authority, Region Västerbotten.

Competing interests None declared.

Patient consent for publication Not applicable.

Ethics approval Ethical approval has been granted by the Swedish National Research Ethical Review authority (document number 2019-06525, Ethical review board chairman Peter Strömberg). The data have been anonymised prior to processing with original patient record access only made available to the primary investigator.

Provenance and peer review Not commissioned; externally peer reviewed.

Data availability statement Data are available upon reasonable request. The datasets analysed can be made available from the corresponding author on reasonable request.

Supplemental material This content has been supplied by the author(s). It has not been vetted by BMJ Publishing Group Limited (BMJ) and may not have been peer-reviewed. Any opinions or recommendations discussed are solely those of the author(s) and are not endorsed by BMJ. BMJ disclaims all liability and responsibility arising from any reliance placed on the content. Where the content includes any translated material, BMJ does not warrant the accuracy and reliability of the translations (including but not limited to local regulations, clinical guidelines, terminology, drug names and drug dosages), and is not responsible for any error and/or omissions arising from translation and adaptation or otherwise.

Open access This is an open access article distributed in accordance with the Creative Commons Attribution Non Commercial (CC BY-NC 4.0) license, which permits others to distribute, remix, adapt, build upon this work non-commercially, and license their derivative works on different terms, provided the original work is properly cited, appropriate credit is given, any changes made indicated, and the use is non-commercial. See: http://creativecommons.org/licenses/by-nc/4.0/.

\section{ORCID iDs}

Marcus Fredriksson Sundbom http://orcid.org/0000-0002-3586-4197

Michael Haney http://orcid.org/0000-0002-4049-8910
REFERENCES

1 Brändström H, Winsö O, Lindholm L, et al. Regional intensive care transports: a prospective analysis of distance, time and cost for road, helicopter and fixed-wing ambulances. Scand J Trauma Resusc Emerg Med 2014;22:36.

2 Macartney I, Nightingale P. Transfer of the critically ill adult patient. BJA CEPD Reviews 2001;1:12-15.

3 Chang JC-Y, Huang H-H, Chang S-H, et al. Clinical predictors of outcomes in patients undergoing emergency air medical transport from Kinmen to Taiwan. Medicine 2017;96:e8440.

4 Sunde GA, Sandberg M, Lyon R, et al. Hypoxia and hypotension in patients intubated by physician staffed helicopter emergency medical services - a prospective observational multi-centre study. BMC Emerg Med 2017;17:22.

5 Droogh JM, Smit M, Absalom AR, et al. Transferring the critically ill patient: are we there yet? Critical Care 2015;19:62.

6 ARDS Definition Task Force, Ranieri VM, Rubenfeld GD, et al. Acute respiratory distress syndrome: the Berlin definition. JAMA 2012;307:2526-33.

7 Chen W-L, Ma H-P, Wu C-H, et al. Clinical research of mortality in emergency air medical transport. Biomed Res Int 2014;2014:1-5.

8 Kashyap R, Anderson PW, Vakil A, et al. A retrospective comparison of helicopter transport versus ground transport in patients with severe sepsis and septic shock. Int J Emerg Med 2016;9:15.

9 Shankar-Hari M, Ambler M, Mahalingasivam V, et al. Evidence for a causal link between sepsis and long-term mortality: a systematic review of epidemiologic studies. Crit Care 2016;20:101.

10 Wang HE, Szychowski JM, Griffin R, et al. Long-Term mortality after community-acquired sepsis: a longitudinal population-based cohort study. BMJ Open 2014;4:e004283.

11 Halmin M, Chiesa F, Vasan SK, et al. Epidemiology of massive transfusion: a binational study from Sweden and Denmark. Crit Care Med 2016;44:468-77.

12 Mitra B, Gabbe BJ, Kaukonen K-M, et al. Long-Term outcomes of patients receiving a massive transfusion after trauma. Shock 2014;42:307-12.

13 Bilan N, Dastranji A, Ghalehgolab Behbahani A. Comparison of the spo2/fio2 ratio and the pao2/fio2 ratio in patients with acute lung injury or acute respiratory distress syndrome. J Cardiovasc Thorac Res 2015;7:28-31.

14 Brown SM, Grissom CK, Moss M, et al. Nonlinear imputation of Pao2/Fio2 from Spo2/Fio2 among patients with acute respiratory distress syndrome. Chest 2016;150:307-13.

15 Wang CY, Calfee CS, Paul DW, et al. One-Year mortality and predictors of death among hospital survivors of acute respiratory distress syndrome. Intensive Care Med 2014;40:388-96.

16 Davidson TA, Rubenfeld GD, Caldwell ES, et al. The effect of acute respiratory distress syndrome on long-term survival. Am J Respir Crit Care Med 1999;160:1838-42.

17 Wilcox SR, Richards JB, Genthon A, et al. Mortality and resource utilization after critical care transport of patients with hypoxemic respiratory failure. J Intensive Care Med 2018;33:182-8.

18 Peek GJ, Mugford M, Tiruvoipati R, et al. Efficacy and economic assessment of conventional ventilatory support versus extracorporeal membrane oxygenation for severe adult respiratory failure (CESAR): a multicentre randomised controlled trial. The Lancet 2009;374:1351-63.

19 Gebremichael M, Borg U, Habashi NM, et al. Interhospital transport of the extremely ill patient: the mobile intensive care unit. Crit Care Med 2000;28:79-85.

20 Meisler R, Thomsen AB, Abildstrøm H, et al. Triage and mortality in 2875 consecutive trauma patients. Acta Anaesthesiol Scand 2010;54:218-23.

21 Moen KG, Klepstad P, Skandsen T, et al. Direct transport versus interhospital transfer of patients with severe head injury in Norway. Eur J Emerg Med 2008;15:249-55.

22 Rivara FP, Koepsell TD, Wang J, et al. Outcomes of trauma patients after transfer to a level I trauma center. J Trauma 2008;64:1594-9.

23 de Rooij SE, Abu-Hanna A, Levi M, et al. Factors that predict outcome of intensive care treatment in very elderly patients: a review. Crit Care 2005;9:R307-14.

24 LeBlanc CH, Tallon JM, Ackroyd-Stolarz S. Geriatric air medical transport: a program review. Air Med J 2002;21:38-40.

25 Werman HA, Darbha S, Cudnik M, et al. Do trauma patients aged 55 and older benefit from air medical transport? Prehosp Emerg Care 2017;21:461-5.

26 Sullivent EE, Faul M, Wald MM. Reduced mortality in injured adults transported by helicopter emergency medical services. Prehosp Emerg Care 2011;15:295-302. 